\title{
A MULHER DENTRO DOS MOVIMENTOS SOCIAIS DO CAMPO: EMANCIPAÇÕES EM DISPUTA NA CONSTRUÇÃO DE PROTAGONISMOS
}

\author{
THE WOMAN WITHIN THE SOCIAL MOVEMENTS OF THE FIELD: \\ EMANCIPATIONS IN DISPUTE IN THE CONSTRUCTION OF PROTAGONISMS
}

Allene Lage $\boldsymbol{I}^{1}$

\begin{abstract}
RESUMO
Este artigo reúne os resultados do projeto de produtividade científica A MULHER NOS MOVIMENTOS SOCIAIS DO CAMPO. Identidades, saberes de luta e educação. Um estudo comparado entre as mulheres do Movimento Sem Terra e as do Movimento das Mulheres Trabalhadoras Rurais, financiado pelo CNPq. O projeto tratou de vários fenômenos inerentes às questões da mulher dentro dos movimentos sociais do campo, tais os processos sociais de (in)visibilização produzidos sobre as mulheres camponesas, as estratégias de luta adotadas pelas mulheres dentro dos movimentos sociais para a sua afirmação no âmbito das relações de gênero, as violências contra a mulher e o trabalho pedagógico de dentro dos movimentos sociais do campo em Pernambuco para a igualdade de nas relações de gênero, as repercussões no interior dos movimentos sociais referentes às dimensões de raça, etnia, geração e orientação sexual das mulheres que participam do movimento, as vivências que provocam a construção de novos processos identitários, os protagonismos das mulheres no contexto da função social da terra dentro dos movimentos sociais do campo em Pernambuco, e as aprendizagens políticas que as trabalhadoras rurais ensinam às suas filhas; o que refletiu os objetivos específicos do projeto de produtividade e que, para sua realização foram divididos em sub-projetos. Esta pesquisa foi fundamentada pelo Método do Caso Alargado (SANTOS, 1983) por proporcionar um exame mais abrangente sobre as várias implicações do estudo da mulher dentro dos movimentos sociais do campo em Pernambuco. As nossas conclusões apontam que as experiências dessas mulheres dentro desses movimentos sociais, as colocam numa luta por emancipações cotidiana, onde se constroem protagonistas nas lutas por cidadania.
\end{abstract}

Palavras-chave: mulher; trabalhadora rural; MST; MMTR-NE; movimentos sociais do campo.

\begin{abstract}
This article brings together the results of the scientific productivity project THE WOMAN IN THE SOCIAL MOVEMENTS OF THE FIELD. Identities, knowledge of struggle and education. A comparative study between the women of the Landless Movement and those of the Movement of Rural Women Workers, funded by CNPq. The project dealt with various phenomena inherent in women's issues within the social movements of the countryside, such as the social processes of (in)visibilization produced on peasant women, the strategies of struggle adopted by women within social movements for their affirmation within gender relations, violence against women and pedagogical work within the social movements of the countryside in Pernambuco for equality in gender relations, repercussions within social movements on the dimensions of race, ethnicity, generation and sexual orientation of the women participating in the movement, the experiences that lead to the construction of new identity processes, the role of women in the context of the social function of the land within the social movements of the countryside in Pernambuco, and the political learning that rural workers teach their daughters; which reflected the specific objectives of the productivity project
\end{abstract}

\footnotetext{
${ }^{1}$ Pós-doutora em Direitos Humanos (PPGDH/UFPE, 2016). Pós-doutora em Educação (UFRGS, 2012). Doutora em Sociologia (Universidade de Coimbra, 2006). Professora Associada da Universidade Federal de Pernambuco. Professora do Programa de Pós-graduação em Educação Contemporânea do Programa de Pós-graduação em Direitos Humanos. e-mail: allenelage@yahoo.com.br
}

Revista Debates Insubmissos, Caruaru, PE. Brasil, v.1, n.1, jan./abr. 2018. Endereço: https://periodicos.ufpe.br/revistas/debatesinsubmissos/ 
and which, for its realization, were divided into sub-projects. This research was supported by the Alargado Case Method (SANTOS, 1983) for providing a more comprehensive examination of the various implications of the study of women within the social movements of the countryside in Pernambuco. Our conclusions point out that the experiences of these women within these social movements, put them in a struggle for emancipations on a daily basis, where they build protagonists in the struggles for citizenship.

Keywords Women; Rural workers; MST; MMTR-NE; Social movements of the countryside.

\section{INTRODUÇÃO}

As mulheres camponesas, além variadas questões que envolvem os processos de subalternização, convivem na maioria das vezes com o isolamento a que vivem muitas famílias, a dificuldade de locomoção e dos acessos aos processos educacionais e formativos. Desta forma a organização destas mulheres para lutar contra as diversas formas de opressão ou para terem consciências delas, torna-se mais difícil do que as mulheres que vivem nas cidades, que dispõem de muitos mais recursos sociais para tal intento.

De fato, a ausência de recursos sociais para a promoção de processos de reflexão e de organização social das mulheres, tem sido um dos maiores entraves para a luta por cidadania das mulheres, principalmente nas do campo. Contudo estes fatores por si só, não são os únicos responsáveis pelo o entraves e/ou êxitos das lutas por cidadania de muitas mulheres, pois se assim fosse estaríamos a admitir que a luta só seria possível se impulsionada por recursos externos. Contudo, ao contrário, a luta nasce com maior freqüência no seio dos/as excluídos/as e muitas vezes são apropriadas por atores sociais externos.

No que concerne a idéia de luta pela afirmação de direitos de igualdade, de uma nova identidade ou consciência capaz de mobilizar mulheres para a ação política de transformação social, Boaventura de Sousa Santos (1999) afirma, ao discutir o tema os Novos Movimentos Sociais, que estes trouxeram novos fatores de análise na relação regulação-emancipação e na relação subjetividade-cidadania. Na relação subjetividade-cidadania defende a idéia de que estes representam a afirmação da subjetividade perante a cidadania. Acrescenta ainda que a emancipação por que lutam não é política, mas, antes, pessoal, social e cultural e que os protagonistas dessas lutas não são as classes sociais, são grupos sociais, ora maiores, ora menores 
que classes, com contornos mais ou menos definidos em vista de interesses coletivos por vezes muito localizados, mas potencialmente universalizáveis.

Tendo em conta esta discussão na perspectiva desta relação subjetividade-cidadania, o nosso projeto de pesquisa nos motiva a fazer duas perguntas:

- Qual o lugar social da mulher dentro dos movimentos sociais do campo?

- Como suas experiências dentro dos movimentos sociais têm contribuído para a (re)construção de novas subjetividades?

\section{A MULHER DO CAMPO NO ESPAÇO DO DESENVOLVIMENTO RURAL}

Se até o princípio da década de 1970 a discussão sobre mulher ou sobre relações de gênero no mundo rural era praticamente ausente ${ }^{2}$, foi a partir do trabalho de Ester Boserup ${ }^{3}$ que as preocupações com estes temas no desenvolvimento começaram a aparecer nos discursos de desenvolvimento de modo mais abrangente. De fato, nos anos 1970, o tema das relações de gênero foi trazido à tona pelo trabalho de Ester Boserup. Neste trabalho a autora analisou projetos

de desenvolvimento na Ásia, na África e na América Latina e demonstrou como os homens se foram apropriando da técnica e dos resultados da modernização tecnológica, introduzida na área agrícola, ao mesmo tempo em que as mulheres foram sendo excluídas e fixadas nas atividades de tecnologia tradicional, de menor rendimento e de menores ganhos financeiros. $\mathrm{O}$ estudo afirmou assim que, ao contrário do que muitos esperavam, a modernização na esfera produtiva, se não acompanhada pela democratização das relações sociais, dificilmente promoverá o equacionamento das desigualdades sociais, onde a de gênero é uma delas.

\footnotetext{
${ }^{2} \mathrm{O}$ que se encontrava, em termos de gênero nas políticas públicas, estava geralmente relacionado com o aspecto reprodutivo e doméstico da mulher ou, então, com algum tipo de produção local, em pequena escala e geralmente em condições semi-precárias.

3 Nos anos 1970, o tema das relações de gênero foi trazido à tona pelo trabalho de Ester Boserup, intitulado Women's Role in Economic Development. Neste trabalho a autora analisa projetos de desenvolvimento na Ásia, na África e na América Latina e demonstra como os homens se foram apropriando da técnica e dos resultados da modernização tecnológica, introduzida na área agrícola, ao mesmo tempo que as mulheres foram sendo excluídas e fixadas nas atividades de tecnologia tradicional, de menor rendimento e de menores ganhos financeiros. $\mathrm{O}$ estudo afirmou assim que, ao contrário do que muitos esperavam, a modernização na esfera produtiva, se não acompanhada pela democratização das relações sociais, difícilmente promoverá o equacionamento das desigualdades sociais, onde a de gênero é uma delas (BOSERUP, 1970).
} 
Por sua vez, para Arturo Escobar (1994), o papel das mulheres no desenvolvimento em vários estudos, tendo por referência principal Ester Boserup, mostrou que aquele tipo de desenvolvimento não só contribuiu para a invisibilidade das mulheres na economia, como também teve um efeito na posição econômica e no estatuto das mulheres, pois além das difíceis condições em que vivem, ainda tiveram ampliadas a carga de trabalho, ao virem-se envolvidas em intervenções ao desenvolvimento.

Contudo com a participação subalternizada das mulheres, elas não conseguiram modificar suas condições sociais e, em muitos casos, o estado do trabalho de mulheres piorou com a exclusão provocada pelos programas de desenvolvimento agrícolas. A razão para esta exclusão estava relacionada ao preconceito masculino de desenvolvimento e ao modelo escolhido, o de agricultura norte-americana (ESCOBAR, 1994, p. 171).

Nesta mesma direção, Escobar conclui dizendo, que as mulheres foram os "fazendeiros" invisíveis, ou para ser mais preciso, a invisibilidade das mulheres foi organizada por conhecimentos e técnicas que consideraram seu papel apenas como reprodutoras. No final dos anos setenta, as mulheres apareceram para o aparato de desenvolvimento somente como mães grávidas ou amamentando os bebês, procurando água ou comida e cuidando do lar, lidando com as doenças de crianças, ou, no melhor de casos, cuidando da horta para completar a dieta familiar. Tal era a extensão das vidas de mulheres presente na maioria da literatura de desenvolvimento. Neste sentido, este autor acrescentou ainda, que só os homens eram ocupados em atividades produtivas, e, por conseguinte, com a melhoria da produtividade agrícola. Nos casos onde as mulheres recebiam treinamentos, referiam-se às áreas consideradas naturalmente destinadas à elas, como coser ou habilidades manuais (IBIDEM).

Por fim, Escobar conclui sua análise ao dizer, que a maioria dos peritos de agricultura e agentes de extensão é masculina, treinada por peritos masculinos, e preparados para suprir e interagir principalmente com fazendeiros masculinos; os beneficiários de quaisquer melhorias sociais e tecnológicas que acontecem em agricultura, eles são os receptores de inovações, à eles são destinadas as melhores terras, a concentração na produção de produtos com valor de mercado mais alto e, em face disso participam mais inteiramente com dinheiro na economia local e 
regional. Inevitavelmente, o estado do trabalho de mulheres é banido para as atividades de subsistência. Quando acontecerem melhorias técnicas em atividades produtivas que são dominadas por mulheres, estas normalmente são transferidas aos homens; por exemplo, quando uma colheita realizada por mulheres é mecanizada, o controle de tratores ou ferramentas não vai para mulheres, mas para homens (IBIDEM).

A análise de Escobar mostra que as estratégias de desenvolvimento e de modernização nunca tencionaram promover qualquer tipo justiça social e ou igualdade de condições na relação de gênero, quer seja socialmente, na questão da produção ou mesmo dentro do domínio do desenvolvimento, quer seja devido a sua condição de invisibilidade, decorrente de sua subalternidade naturalizada, que lhes retira qualquer possibilidade de serem percebidas como detentoras dos mesmos direitos aos recursos que os homens têm, pois está socialmente consagrada, tanto pelos agricultores, como pelos técnicos e como também dentro dos próprios programas, a sua condição de inferioridade.

No âmbito dos projetos de desenvolvimento, surgiu, a partir do estudo de Boserup, o enfoque Mulheres no Desenvolvimento (MED) ${ }^{4}$ que, de modo geral, trata de implementar de forma prioritária programas específicos para aumentar a participação da mulher nos processos de desenvolvimento $^{5}$. O problema desta abordagem, é a sua despolitização, já que as mulheres são pensadas individualmente e fora das relações de gênero. Embora esta perspectiva beneficie muitas mulheres, reduz a questão às políticas de atendimento e de reprodução, sem contemplar as desigualdades de gênero entre mulheres e homens.

Neste sentido, Santos (1999) diz que, depois do trabalho de Esther Boserup ${ }^{6}$ tem prevalecido a tendência para distinguir entre as posições das mulheres nos países do Norte e nos

\footnotetext{
${ }^{4}$ Frequentemente referenciado como WID (Women in Development).

${ }^{5}$ A partir de 1975, cresce, na esfera internacional, a presença das questões de gênero. São marcos desse processo a Década da Mulher, 1975-1985, instituída pela ONU, e o Ciclo Social de conferências das Nações Unidas, realizado durante os anos 1990, culminando com a IV Conferência sobre Mulher, Desenvolvimento e Paz, em Pequim, 1995.

${ }^{6}$ Para Santos são três os argumentos principais apresentados por Boserup em seu trabalho Women's Role in Economic Development. O primeiro a transição da chamada sociedade tradicional para a chamada sociedade moderna tem envolvido sempre a queda do status social das mulheres; o segundo é o aumento do nível tecnológico da produção agrícola e da produção industrial afeta negativamente a taxa de emprego das mulheres, relativamente à dos homens e o terceiro é que em toda a parte há certas tarefas, nomeadamente as relacionadas com a subsistência,
} 


\section{Revista \\ Debates Insubmissos}

países do Sul. Contudo, conforme argumenta este autor corre-se o risco de criar uma imagem abstrata da "mulher do Terceiro Mundo", perdendo de vista as diferenças da situação das mulheres em diferentes países do Terceiro Mundo e as diferenças de classe das mulheres no interior de cada país (SANTOS, 1999, p. 303).

Santos tem razão ao referenciar o risco da generalização para a construção de um padrão sobre a "mulher do Terceiro Mundo". Para além da definição de um perfil de subalternidade, feito a partir do olhar do Norte existe outro problema que está implícito na crítica aos projetos de desenvolvimento $^{7}$, que é o de fazer da vida das mulheres do Primeiro Mundo, o padrão, desejado e carenciado pelas mulheres do Terceiro Mundo.

Nos anos 1980, surge a abordagem Gênero e Desenvolvimento (GED) ${ }^{8}$, desta vez mais vocacionado para tratar as questões de gênero, visando transformar estas relações e proporcionar condições para o empoderamento das mulheres. Em seu âmago veio defender que o problema de gênero não pode ser tratado somente por meio de ações para incorporar a mulher nas ações do desenvolvimento, se ela continua dentro de uma relação de subalternidade. Neste sentido, esta perspectiva marca uma mudança de preocupações e um novo interesse pelas relações de gênero e não apenas pelas mulheres.

Tanto na concepção do MED quanto do GED -, o problema do gênero estava vinculado à questão do desenvolvimento. No fundo estas abordagens oferecem estratégias que, em alguma medida, permitem alcançar melhor objetivos determinados para o desenvolvimento ${ }^{9}$. Neste

\footnotetext{
que são quase exclusivamente desempenhadas por mulheres (SANTOS, 1999, p. 303).

${ }^{7}$ Segundo Santos e Rodrigues (Santos, 2000), em termos gerais, os projetos de desenvolvimento económico foram concebidos e implementados "a partir de cima" (top-down development), com base em políticas traçadas e implementadas por agências tecnocráticas nacionais e internacionais, sem a participação das comunidades afectadas por essas políticas. Além do mais, os planos de desenvolvimento estavam tradicionalmente centrados na aceleração do crescimento económico, principalmente do sector industrial (Cypher e Dietz, 1997). Esta ênfase evidente nos resultados macroeconómicos implicou a marginalização de outros objectivos sociais, económicos e políticos, como a participação democrática na tomada de decisões, a distribuição equitativa dos frutos do desenvolvimento e a preservação do meio ambiente (SANTOS E RODRIGUEZ, 2002, p. 45).

${ }^{8}$ Comumente referenciado como GAD (Gender and Development).

${ }^{9}$ Para Escobar, a idéia básica de desenvolvimento tem permanecido inalterada, pois o desenvolvimento continua a ser considerado como um princípio central organizador da vida social, assim como o feito de que a Ásia, África e América Latina puderam definir-se como subdesenvolvidas e que suas populações se acharam irremediavelmente necessitadas de "desenvolvimento", seja qual for a forma que tome (ESCOBAR, 2000).
} 
sentido, é mais comum à questão de gênero aparecer associada apenas ao tema da pobreza das mulheres, abstraída de qualquer perspectiva histórica sobre as desigualdades na relação mulher e homem, distanciando-se, em muito, da forma e do sentido do problema de gênero, tal qual é discutido pelas correntes do feminismo.

Maria da Glória Gohn (2002), aponta uma diferença importante entre a América Latina e Europa no que diz respeito ao foco da participação das mulheres na década de 1980. A sua perspectiva é reveladora dos impactos das perspectivas do MED e GED, via projeto de desenvolvimento para o Terceiro Mundo.

[...] os movimentos populares no Brasil, como no conjunto da América Latina, trouxeram à cena política, de forma majoritária, a participação das mulheres. Enquanto na Europa esta presença se fez em torno das questões de gênero, na América Latina o movimento feminista foi importante, mas circunscrito a grupos específicos, mais intelectualizados. O maior contingente de participação de mulheres foi nos movimentos populares, como de mandatárias de reivindicações populares por melhorias, serviços e equipamentos coletivos, e não como de mandatárias de direitos de igualdade entre os $\operatorname{sexos}(\mathrm{GOHN}, 2002$, p. 293).

De fato, se por um lado as mulheres da América Latina ampliaram a disponibilidade de equipamentos sociais por meio de suas lutas, pelo outro lado, os avanços não foram tão visíveis no campo das relações de gênero, mas foi lento e progressivo. Neste mesmo cenário, João Francisco de Souza (1999), alerta sobretudo para o fato de que as relações sociais de gênero nos movimentos sociais da América Latina, não foram bem compreendidas em alguns destes movimentos, pois quando se falava de relações sociais de gênero compreendiam-se apenas os problemas específicos do gênero feminino e, nesta medida, o importante é não esquecer que se trata de relações sociais de gênero (SOUZA, 1999, p. 175).

Tanto o argumento de Gohn quanto o de Souza, ajudam-nos a compreender a lógica que está por trás da questão de gênero, quando esta entra nos movimentos sociais, como também nos projetos de desenvolvimento, o que em boa medida reforça o impacto e a ênfase dada aos recursos para a participação das mulheres no âmbito destes projetos e dos movimentos sociais.

No caso das mulheres da Europa, esta questão avança um pouco pelo fato de que os recursos não estavam amarrados a um tipo de participação e, neste ponto, parece certo afirmarmos que não estando contextualizadas num projeto de desenvolvimento, as lutas feministas tiveram 
mais manobra para aprofundar a questão das relações de gênero. Entretanto, mesmo perante as conquistas feministas para a inclusão da questão do gênero, das lutas para "dessubalternizar" a presença das mulheres nos planos de desenvolvimento, parece que muitos organismos - nacionais e internacionais - pouco mudaram, se considerarmos os critérios e indicadores utilizados para medição do sistema produtivo.

Neste sentido, Santos e Rodriguez (2002) aludem que um dos efeitos mais interessantes da luta pelo reconhecimento do trabalho feminino - especialmente o trabalho doméstico que, pela sua invisibilidade pública, fica fora dos cálculos econômicos convencionais, como o Produto Interno Bruto - tem sido o questionamento do próprio conceito de atividade econômica e da forma de medir o que conta como produção. Estes autores, referindo-se ainda à outros estudos, reforçam o discurso sobre a necessidade de incluir o trabalho não-remunerado na formulação de concepções políticas e econômicas que eliminem a discriminação contra as mulheres dos programas econômicos convencionais, pois as propostas de desenvolvimento alternativo têm demonstrado, convincentemente, que o conceito e as medidas convencionais da produção são inadequadas, uma vez que deixam de fora dos registros muitas das atividades desempenhadas pelas mulheres (SANTOS E RODRIGUES, 2002, p. 49).

\section{METODOLOGIA}

A metodologia utilizada na execução do projeto esteve orientada para estudar os fenômenos envolvidos sobre a mulher dentro dos movimentos sociais do campo em Pernambuco. Procurando compreender os caminhos para as suas emancipações, suas resistências e transgressões, em face ao desafio de superação das opressões, das invisibilidades, da construção de novas identidades, de novos saberes, buscou desconstruir suas ausências e suas subalternizações.

\subsection{Método do Caso Alargado}

Esta pesquisa foi analisada pelo Método do Caso Alargado que tem como base procedimental o Estudo de Caso, que é importante para a compreensão do tema pesquisado, por 
proporcionar um exame mais abrangente sobre as várias implicações do estudo da mulher dentro dos movimentos sociais do campo em Pernambuco.

Após esta análise holística do caso, foi ampliado o universo das implicações sobre o estudo. Dentro desta perspectiva, o Método do Caso Alargado consubstancia a necessidade de ampliar as conclusões do estudo de caso, pela especificidade do tema da pesquisa. Assim, elegemos o método do caso alargado, utilizado por Boaventura de Sousa Santos (1983) e posteriormente por Michael Burawoy (1991; 2000), e por Lage (2005) para fins desta pesquisa, de modo a viabilizar uma comparação entre dois movimentos sociais do campo que atuam no estado de Pernambuco.

\subsection{A comparação entre as duas experiências de mulheres trabalhadoras rurais}

Quanto a comparação entre as ações políticas das mulheres do MST -PE e das mulheres do MMTR-NE, partimos da compressão de Lage (2005) que afirma que não se deve realizar uma comparação entre as lutas sociais, pretendendo apontar prós e contras, colocando-as numa disputa política, pois comparar é estabelecer pontes, aproximar margens, abrir caminhos para o diálogo, e neste sentido deve-se procurar, ao comparar, ampliar o universo das possibilidades das experiências que compara, de modo que, a partir desta diversidade, seja possível olhar para as sociedades e reconhecer os caminhos e as conquistas alcançadas (LAGE, 2005, p. 676).

Ainda para Lage (2005), uma comparação entre duas ou mais experiências só faz sentido à luz destes contextos, sobretudo quando se identifica os diferentes modos de ação e o êxito relativo, com que cada experiência responde ao seu cenário social e como estas procuram superar, por meio dos seus processos de luta, resistência as experiências a que estão submetidos (IBIDEM, p. 611).

\subsection{As técnicas de coleta de dados}

A coleta de dados foi realizada por meio de encontros de formação, reuniões e de entrevistas que serviram de guia para conduzir as conversas, de modo que não reduziu as possibilidades de um conhecimento mais profundo sobre as mulheres dentro dos movimentos sociais do campo. Para tanto utilizamos várias técnicas de coleta de dados como a observação- 
participante, as conversas informais, as entrevistas semi-estruturadas e as histórias de vida/oral. Para além dos encontros, a pesquisa contemplou uma vasta consulta bibliográfica e documental em bibliotecas locais, incluindo estudos e reflexões sistematizadas sobre a questão da mulher no campo e/ou sobre movimentos sociais.

\subsection{Universo da Pesquisa - MST-PE E MMTR-NE}

O Universo da nossa pesquisa foi representado por dois importantes movimentos sociais: $\mathrm{O}$ Movimento dos Trabalhadores Rurais Sem Terra de Pernambuco e o Movimento das Mulheres Trabalhadoras Rurais do Nordeste. A escolha destas duas experiências se deu em primeiro lugar por se tratarem de dois reconhecidos movimentos sociais do campo e em segundo lugar pelo tempo da vida destas experiências.

- Movimento dos Trabalhadores Rurais Sem Terra - Pernambuco

O Movimento dos Trabalhadores Rurais Sem Terra - MST tem sua origem no final da década de 1970, num cenário de fim de ditadura militar, abertura política e retomada do processo de democratização do Brasil. Uma ação tornou-se o marco para o início do MST que foi a primeira ocupação de terra - a gleba Macali, em Ronda Alta, em 7 de setembro de 1979, realizada por um grupo de agricultores sem terra no estado do Rio Grande do Sul, apoiados pela Comissão Pastoral da Terra. Após este evento, novas ocupações ocorreram, paralelamente, nos Estados de Mato Grosso e São Paulo, impulsionando a organização dos trabalhadores rurais em vários estados do Brasil. No ano de 1989 o MST realiza no Estado de Pernambuco a primeira ocupação de terra com grande expectativa, pois o Movimento Sem Terra contava com a história de luta dos trabalhadores e trabalhadoras da região. Contava ainda com o apoio do então governador Miguel Arraes, que tinha uma história muito vinculada às grandes lutas dos camponeses da Zona da Mata de Pernambuco, principalmente porque fora governador do Estado durante o auge das lutas das Ligas Camponesas. Segundo Amorim e Souza (2008) a lógica do surgimento do Movimento dos Trabalhadores Rurais Sem Terra na Zona da Mata do Estado de Pernambuco se deu a partir da estratégia de expandir a bandeira da luta da Reforma Agrária e resgatar as lutas históricas do povo nordestino, levando em conta as lutas pela terra já desenvolvidas nesta região. Um marco importante do da luta do MST em 
Pernambuco na região do Agreste foi a ocupação da Fazenda Normandia, por 179 famílias no dia primeiro de maio de 1993. Para Amorim e Souza (2008), a ocupação se transformou em símbolo de resistência e de luta, pois foram quatro despejos e cinco ocupações até a vitoria definitiva, em novembro de 1997.

\section{- Movimento das Mulheres Trabalhadoras Rurais - Nordeste}

O Movimento da Mulher Trabalhadora Rural do Nordeste - MMTR-NE nasceu das reflexões e do intercâmbio de mulheres em duas micro-regiões dos estados de Pernambuco e Paraíba, na década de 1980. A participação destas mulheres no III Encontro Feminista Latino-Americano e do Caribe, em 1985, foi um momento muito importante para fortalecer essa definição. Assim, inicia-se a articulação nos nove estados do Nordeste. O MMTR-NE com sede por vinte e um anos em Pernambuco, surgiu a partir de demandas que agregavam a condição de trabalhadora rural, a experiência das mulheres em mobilizações nas frentes emergenciais e por direitos previdenciários. Este movimento começou a se organizar a partir da discussão das dificuldades, dos sonhos e dos desafios de grupos de mulheres das áreas rurais da Paraíba e de Pernambuco na década de 1980. Atualmente, são mais de três mil mulheres organizadas, lideranças de organizações de base comunitária em nove estados (Alagoas, Bahia, Ceará, Maranhão, Pernambuco; Piauí, Paraíba, Rio Grande do Norte, e Sergipe). Atualmente, com sede em Caruaru (Pernambuco), a organização conta com coordenações municipais e estaduais, diretoria composta por duas mulheres em cada estado da Região Nordeste e uma secretária executiva. A temática mais discutida é a violência contra a mulher, pois esta é uma realidade enfrentada por muitas mulheres, particularmente em Pernambuco, que é um dos estados brasileiros onde há um maior índice de violência e crimes contra a mulher. Uma vertente educativa importante do MMTR-NE é o trabalho de resgate da identidade e promoção da autoestima das mulheres.

Mesmo havendo diferenças entre os dois movimentos, especialmente porque um contempla as lutas de gênero entre mulheres e homens dentro da mesma organização e dentro de uma luta maior e, o outro a luta de gênero dentro de uma organização somente de mulheres, há entre estas experiências uma convergência dos limites, dificuldades e dos esforços por mudarem 
as relações de gêneros e a preocupação com melhores condições de vida para as mulheres do campo.

\section{PRINCIPAIS RESULTADOS ALCANÇADOS SOBRE O ESTUDO DA MULHER DENTRO DOS MOVIMENTOS SOCIAIS DO CAMPO MST-PE E DO MMTR-NE}

\subsection{Principais processos sociais de (in)visibilização produzidos sobre as mulheres camponesas $^{10}$}

Estes Movimentos possuem singularidades que são muito claras no que concerne as invisibilidades vivenciadas pelas mulheres, embora o MMTR/NE seja contituído apenas por mulheres, elas percebem que as mulheres sofrem com a invibilidades de sua identidade e subjetividade por meio desses processos sociais que estão presentes numa sociedade sexista, patriarcal, de classes, onde é negado o acesso à educação, a participação política e o não reconhecimento do seu trabalho como gerador de renda e valor social.

Vale ressaltar que no início deste estudo elencamos estes processos como responsáveis por esta exclusão social que é objetiva e subjetiva. Salientamos ainda que no decorrer das nossas observações, estas nos permitiram inferir que a religião também se configurava em um desses processos, sendo, pois, o processo mais dificil de ser combatido, na medida em que é a própria negação da condição de mulher invisibilizada, em consonância com o discurso religioso.

Para sair deste lugar de subalternidade e invisibilidade do processo de exclusão social, as mulheres destes Movimentos utilizam várias estratégias. As principais estão voltadas para o fortalecimento mútuo de suas lutas tanto no espaço doméstico quanto no espaço público da produção, da educação e da participação política, que possam romper com as violências em todos os campos sociais em que estas mulheres atuam. Por isso elas buscam assumir espaços de lideranças tanto no MMTR-NE como no MST, que embora sempre divida os espaços de liderança com os homens, buscam estudar, participar politicamente das ações do movimento, reivindicando

\footnotetext{
${ }^{10}$ Síntese dos resultados e conclusões do Sub-projeto: Identidades e (in) visibilidades: refletindo os processos de construção das ausências e subalternizações das mulheres dentro dos movimentos sociais do campo de Pernambuco, desenvolvido por Maria Guadalupe de Araújo Silva orientado por Allene Lage.
} 
os seus direitos e do coletivo de mulheres que fazem parte deste movimento, buscando de fato o empoderamento.

Com o projeto concluído, as nossas considerações diante das observações e dos dados coletados dos movimentos do MST e MMTR/NE, percebemos que a luta contra os processos de invisibilização das mulheres dos movimentos sociais do campo ocorre por meio de processos educativos e de vivências políticas, que envolve a compreensão da necessidade de construção e reelaboração de saberes, para o enfrentamento dos processos que invisibilizam as mulheres dentro dos movimentos sociais do campo. E o que emerge dentro das mulheres desses Movimentos é um desejo de emancipação plena que lhes propicia vida digna e com respeito, equidade social e novas concepções de relação de gênero, nos assentamentos, em suas casas, em seu trabalho, nos espaço políticos-partidários, nas igrejas e em todo espaço social que as mesmas circulem sendo esses fenômenos constituidores de novos processos identitários.

\subsection{Estratégias de luta adotadas pelas mulheres dentro dos movimentos sociais para a sua afirmação dentro das relações de gênero ${ }^{11}$.}

Com base no projeto desenvolvido, os principais indícios nos remeteram a afirmar que a igualdade de gênero ainda é uma conquista que necessita cada vez mais de lutas sociais. Nos permitiu ainda concluir que na sociedade, de modo geral, persiste uma cultura machista, que dificulta as mudanças necessárias para equiparação entre homens e mulheres.

A observação e o diálogo com mulheres ativistas dos dois movimentos sociais pesquisados nos fez perceber que as mulheres do campo, para afirmação da igualdade das relações de gênero e de direitos, muitas vezes travam lutas diárias dentro da própria família, para que possam exercer sua cidadania e para a participação dentro dos movimentos sociais. Nesse sentido, inúmeras mulheres, mesmo estando envolvidas nos movimentos sociais emancipatórios, ainda sofrem algum tipo de discriminação, sobretudo em seus próprios lares. Em contrapartida, a mudança da percepção do que é ser mulher e a consciência da importância de sua participação para ocorrer uma efetiva mudança, nos leva a crer que a mudança pode ser cada vez mais

\footnotetext{
${ }^{11}$ Síntese dos resultados e conclusões do Sub-projeto: Movimentos sociais do campo: relações de gênero e educação, desenvolvido por Emanuely Arco Íris Silva e orientado por Allene Lage.
} 


\section{Revista (O) \\ Debates Insubmissos}

possível. Há consideravelmente na consciência das militantes dos movimentos socais pesquisados, de que a plena cidadania para as mulheres vai além do voto, e por isso suas lutas são aprofundadas, indo desde a garantia de crédito fundiário para as mulheres até o direito de decidir sobre o seu próprio corpo.

Assim, o avanço da conscientização das mulheres sobre a importância de sua luta, nos faz perceber que uma efetiva mudança, onde a utopia se faz concreta, tanto pelas práticas pedagógicas que desenvolvem dentro de suas organizações. No MMTR/NE os encontros, seminários e oficinas, sempre abordam a questão das relações de gênero na sociedade. No MST, embora as mulheres ocupem, na maioria das vezes, espaços destinados a elas, como o controle das escolas dos assentamentos e acampamentos e o controle do lar, há uma efetiva politização destas, no sentido de reconhecer quais seus limites e quais caminhos precisam traçar, bem como estas estão em todas as coordenações dos movimentos.

A sociedade ainda vive questões sociais da mulher, onde seu lugar e seu papel, mesmo com os avanços das últimas décadas com a conquista do direito ao voto, da educação, em especial a superior, culminado na independência financeira, e na presença massiva das mulheres no mercado de trabalho e a frente de pequenos e médios empreedimentos, ainda não superam as discriminações enfrentadas no tocante às relações de gênero em vários campos, tendo que lutar constantemente por novas relações de gênero.

As questões sociais em torno das desigualdades, presentes nas relações de gênero traz intrínseca as relações de subalternidade existente entre o sexo feminino com relação ao masculino, pois estas permeiam as sociedades contemporâneas, reforçando um preconceito entre as tarefas exercidas pelas mulheres em comparação as realizadas pelos homens.

Em diversas instâncias sociais, as mulheres são desvalorizadas tanto nos espaços públicos quanto privados. Assim, o poder desigual que encontramos no cotidiano social está representado nessa construção social de gênero, caracterizada pela dominação masculina e pela subordinação feminina. Nesse sentido, o problema reside na hierarquização dos gêneros, não nas mulheres em si. A questão fundamental para esta mudança, é assegurar que a construção social de gênero dê espaço à diferença e que não contenha uma noção de hierarquia que coloque os homens a um nível superior às mulheres. 


\subsection{Violências contra a mulher e o trabalho pedagógico de dentro dos movimentos sociais do campo para a igualdade de nas relações de gênero ${ }^{12}$}

Observamos que o MST e o MMTR-NE desenvolvem um trabalho voltado para combater todos os tipos de discriminações e subalternizações que são recorrentes nas relações de gênero, principalmente as naturalizações socioculturais que inferiorizam a imagem da mulher.

Foi possível identificar através das nossas visitas ao campo de estudo, que as principais formas de violências vivenciadas atualmente pelas militantes dos movimentos sociais do campo, acontecem no ambiente familiar sendo praticadas por seus próprios companheiros. As violências mais exercidas contra as mulheres do campo são a física e a psicológica, onde estas podem estar imbricadas com a questão autonomia das mulheres sobre o próprio corpo, uma vez que na visão masculina as mesmas são tratadas como propriedade.

É relevante destacar que as mulheres dos movimentos sociais são bastante esclarecidas politicamente sobre as desigualdades históricas que permeiam as relações de gênero, visto que elas compreendem que as desigualdades são resultado da construção da nossa sociedade, que valoriza desde o início dos tempos até os dias atuais a ideologia imposta pelo patriarcado, enfatizando os valores masculinos de modo superior.

Percebemos ainda que as práticas educativas desenvolvidas dentro dos movimentos sociais do campo referente à figura feminina são voltadas para o enfrentamento da violência contra as mulheres, onde acontecem mediante a filosofia de cada instituição, entretanto observamos que o diálogo é um agente transformador preponderante para a efetivação das práticas educativas destes, visto que o diálogo possibilita a construção de uma educação pautada na humanização dos sujeitos como é a educação realizada dentro dos movimentos sociais, ou seja, há a valorização do ser humano nestes.

Com base no que foi exposto, percebemos que os dois movimentos sociais necessitam aprofundar a reflexão sobre as diferentes orientações sexuais, especialmente o MMTR-NE, visto

\footnotetext{
${ }^{12}$ Síntese dos resultados e conclusões do Sub-projeto: Violências contra a mulher e desigualdades nas relações de gênero: o trabalho pedagógico de dentro dos movimentos sociais do campo em Pernambuco para a igualdade de nas relações de gênero, desenvolvido por Míriam Monteiro de Lima e orientado por Allene Lage
} 
que foi perceptível em que neste movimento não há atividades voltadas para as diferentes identidades sexuais. Já o MST criou recentemente um setor sobre as questões LGBT. Por fim compreendemos que a pedagogia utilizada pelos movimentos sociais é coerente com o contexto dos militantes, visto que há difusão de saberes e respeito ao próximo, uma vez que estes pretendem construir uma sociedade comprometimento social e político.

\subsection{Repercussões no interior dos movimentos sociais referentes às dimensões de raça, etnia, geração e orientação sexual das mulheres que participam do movimento ${ }^{13}$.}

As ideologias que demarcam o cotidiano através de institucionalizações reconhecidas e reproduzidas durante os séculos, firmam-se com ideologias hegemônicas, as quais se proliferam nas formações dos sujeitos. Dão ênfase aos cativeiros que se constrói e que são potencializados através da subalternização da Mulher. Nesse sentindo, os cativeiros simbólicos que permeiam os dispositivos sociais, têm marcado as inter-relações existentes, não obstante, os movimentos sociais, marcados por esses simbolismos, lutam contra essas opressões que se estabelecem em âmbitos diferenciados, e que permeiam lugares e poderes consolidando verdades engendradas. As mulheres têm assumido papéis políticos dentro dos movimentos sociais, enfrentando opressões enquanto mulheres organizadas, e politizadas, ganhando visibilidade nas desconstruções das desigualdades sociais, e, sobretudo as que se referem à raça-etnia, geração e sexualidade.

As relações étnico-raciais têm sido permeadas por categorizações sociais, firmando-se dessa forma como cativeiros, portanto, as discussões sobre raça-etnia, nos movimentos sociais do campo ainda estão restritos em termos de formações, requerendo nessa perspectiva, vieses formativos, que alcancem as mulheres da base, as mulheres da liderança, e, alcance a sociedade. Compreendemos com isso, a importância de formações que explique e exemplifique o percurso histórico que instituiu o patriarcado, a ideia de raça supostamente superior e inferior, os mecanismos de poder, os quais instituem as desigualdades sociais.

As analogias que se referem às experiências, aos diálogos geracionais, concluímos que são relações simétricas, pelo fato de levar em consideração as especificidades e as singularidades das

\footnotetext{
${ }^{13}$ Síntese dos resultados e conclusões do Sub-projeto: Cativeiros da trabalhadora rural - raça/ etnia, geração e sexualidade: um estudo comparado entre as mulheres do MST-PE e as do MMTR-NE.
} 
mulheres em sua faixa etária, fazendo com que através de relações dialógicas, o conhecimento seja partilhado, e a luta seja consolidada por vias de formações e de ideologias que evidenciam a perspectiva política e formadora que há através dos Movimentos Sociais e com isso os princípios formativos no que se refere aos objetivos por uma sociedade justa, e, sobretudo com paridades em suas ideologias, e seus arcabouços culturais.

No que se refere à sexualidade, os movimentos sociais do campo, tem desconstruído os papéis que são consolidados e firmados ao decorrer dos séculos como um dispositivo cultural, o qual dá um realce à proibições, diante de um sistema de interdições através de uma lógica dominante; instaurando-se como um mecanismo de controle. Apesar disso, concluímos que questões relacionadas às DST's (doenças sexualmente transmissíveis), orientações sexuais que se difere da que é normatizada, a puberdade, precisam estar mais presentes nas formações e nas discussões dos movimentos sociais.

Portanto, as discussões sobre temáticas que fazem parte da construção social, política e identitária, como raça-etnia, geração e sexualidade vêm se fortalecendo, e tem sido conjugado com outras formações e temáticas de maneira a desconstruir cativeiros culturais que permeiam as relações inter-humanas, na luta contra as opressões.

\subsection{Vivências que provocam a construção de novos processos identitários ${ }^{14}$.}

Com a preocupação de ampliar suas incidências para a luta política do MST e MMTRNE, uma de suas contribuições evidencia a compreensão de que a territorialidade contribui para a construção de novas linguagens para a luta política, na medida em que produz uma estabilidade necessária a ação política, sem a qual não seria possível a incorporação de lutadoras permanentes. Ou seja, tem garantido a formação de lideranças em vista das condições para o reconhecimento de pertença. Mas mantém o desafio de reconhecer o multipertencimento de identidades, devido à fragmentação de lutas. Como a territorialidade pode estar sobre o controle dos outros, a alteridade dos grupos se compreende uma tensão na criação e controle dos territórios.

\footnotetext{
${ }^{14}$ Síntese dos resultados e conclusões do Sub-projeto: Territorialidade e linguagens: refletindo a (re)construção das identidades das mulheres dentro dos movimentos sociais do campo de Pernambuco, desenvolvido por Andreia de Lima Silva e orientado por Allene Lage.
} 
A luta contra analfabetismo no MST e MMTR-NE, ao construir referenciais para suas lutas e organização, constroem ligação entre presente e passado, envolvendo nas práticas educativas uma consciência do seu espaço quando influencia outros sujeitos. A memória coletiva é um modo de captura produzindo novos significados para os sujeitos, assim na organização da classe trabalhadora em dado momento histórico constituiu como processo de invisibilização do protagonismo da mulher rural. Atualmente corresponde como processos de empoderamento mediante o coletivo de mulheres, tendo como perspectiva a apropriação dos seus direitos estando inseridas em contextos mais amplos identificam em seus relatos sua desterritorialização como fruto do capitalismo, ampliando seu compromisso com a mudança da sociedade.

Assim, buscam representar na corporeidade, os cenários de contradições, possivelmente na construção de contra-espaços, indicando novas possibilidades de firmar sua identidade, simbolicamente, vestidas ou revestidas com as cores, os gestos fortes e fracos, ritmados, impregnados da linguagem de composição do seu grupo.

\subsection{Protagonismo das mulheres no contexto da função social da terra dentro dos movimentos sociais do campo em Pernambuco ${ }^{15}$.}

Os cativeiros dão a tônica no cotidiano das mulheres do campo, através de deveres tradicionalmente reconhecidos como próprios e naturais. As funções específicas que os sujeitos cumprem, não sendo o único veículo de manutenção de ideologias, tem assegurado à apropriação do corpo da mulher, nos limites de sua efetividade nos espaços de decisão.

O modo como às mulheres tem protagonizado no imaginário o processo de produção de desigualdades e sua implicação em alternativas de organização social, tem como fator para possibilidades de reterritorialidade para manutenção território politicamente mobilizável, a partir das relações de oportunidade de circulação de estratégias ao enfrentamento de exclusões, que são visibilizadas nesse processo. Nesse sentido, a ocupação de espaços de decisão não seria a única

\footnotetext{
15 Síntese dos resultados e conclusões do Sub-projeto: (Re)territorialidade: o protagonismo das mulheres no contexto da função social da terra dentro dos movimentos sociais do campo em Pernambuco, desenvolvido por Andreia de Lima Silva e orientado por Allene Lage.
} 
fonte de produção de autonomias, mas a formações como aprofundamento dos entendimentos voltados para a construção de ações.

Dessa maneira, o conflito de deixar de ser um 'corpo-para-o-outro' para tornar-se um 'corpo-para-si' não quer dizer superação total das questões de subalternidade, mas qualifica uma luta e inserção política das mulheres, em processos dialogados que irão ampliando os referenciais de luta, repercutindo nas relações de gênero, que vão desde as violências contra mulheres à questões propriamente econômicas.

A implementação de políticas governamentais em questões reprodutivas, para a alteridade dos grupos, em sua diversidade de lutas, tem compreendido uma tensão na criação e controle dos territórios. As relações de produção e trabalho das mulheres do campo permitem à assunção da agricultura familiar, e pelo consumo de alimentos, interfere na escolha e relação com o meio ambiente, através de fatores como renda, cooperação técnica, prática de um mercado justo, provavelmente, são os pontos mais potencializadores para formação política dessas mulheres.

Nessa direção, ficam evidentes que as práticas de agenciamentos dos movimentos sociais do campo conduzem processos pedagógicos voltados para a integração das múltiplas exclusões, garantindo uma síntese para efetividade de um desenvolvimento localizado. Tem se revelado com mulheres do MST relações mais simbólicas pelas lutas acirradas ao modelo econômico, contudo no interior das questões de manutenção da vida nos acampamentos e assentamentos tem repercutido na sua identidade de gênero. Com as mulheres do MMTR-E as questões do patriarcado tem produzido a reconstrução de valores culturais por via da constituição de alternativas, para visibilidade como trabalhadora rural.

Os movimentos sociais do campo, com foco nas questões de subalternidade da mulher repercutem na desconstrução de comportamentos naturalizados, e dentro da diversidade cultural que estão inseridos, convergem à vivência de saberes que não podendo ser convertidos em aprendizagens essencializadas, tão pouco, não devem acrescentar uma dimensão única, que representasse toda e qualquer forma de opressão vivenciada pelas mulheres.

As relações que as mulheres tecem em redes de solidariedade com outras mulheres militantes de movimentos sociais do campo, inclusive feministas ao nível global e local, 
aprofundam as relações pelo ao menos em três perspectivas, que são: o fator histórico como identidade territorial comum; o seu papel na opção de sujeito, de consumo ou produtor de benefícios coletivos; e a construção de uma síntese a partir do olhar relacional com as imposições que interferem na politização da trabalhadora rural do seu tempo.

\subsection{Aprendizagens políticas que as trabalhadoras rurais ensinam às suas filhas ${ }^{16}$}

No campo social do conhecimento identificamos nas experiências vividas por trabalhadoras rurais nas relações que estabelecem com suas filhas, a emergência de conhecimentos de lutas que são construídos mediante a participação política dos movimentos sociais do campo, bem como aqueles atrelados a saberes tradicionais de cultivo a terra. Estes conhecimentos são reconhecidos pelas trabalhadoras rurais como arma política na luta que se inserem, e os conhecimentos de luta são responsáveis por uma formação política que apenas esses movimentos sociais do campo propiciam, pois sua estrutura combativa às relações de poder desiguais e opressoras resulta na construção de mulheres militantes que multiplicam esses conhecimentos, sobretudo com as filhas no sentido de formar novas militantes.

No campo social da produção identificamos experiências de grupos de mulheres de cunho cooperativista que constroem sistemas de produção ligados ao autosustento, assim inferimos que os movimentos sociais do campo possuem estas características quanto aos aspectos produtivos, além de conceber indissociavelmente desses processos produtivos as questões relacionadas à sustentabilidade. Tais princípios cooperativistas, construído pelos movimentos sociais do campo, ultrapassam os limites das relações estabelecidas pela organização em si, invadindo os espaços familiares. A mãe possui papel central nesta educação, haja vista que culturalmente foi estabelecida para a mulher a responsabilidade maior na criação dos/as filhos/as.

No campo social do reconhecimento identificamos experiências formativas oriundas dos movimentos sociais do campo que caminham na direção do fortalecimento de identidades emancipatórias. Por essas identidades entendemos aquelas que se relacionam com a afirmação política e cultural da mulher, bem como aquelas que estão carregadas de independência e

\footnotetext{
${ }^{16}$ Síntese dos resultados e conclusões do Sub-projeto: "Quem sai aos seus não degenera". Que experiências políticas as trabalhadoras rurais ensinam às suas filhas? Um estudo comparado entre as mulheres do MST-PE e as do MMTR-NE, desenvolvido por Iasmim de Araujo Vieira e orientado por Allene Lage.
} 
autonomia, como o fortalecimento da profissionalização para esta categoria. Há, neste processo de construção identitária das trabalhadoras rurais, o compartilhamento com suas filhas, contribuindo na construção das identidades das que descendem também.

No campo social da democracia identificamos experiências que nascem da própria estrutura organizativa dos movimentos sociais do campo e que são trazidas, sobretudo pelas mulheres, para o âmbito da família. Assim, compreendemos que as situações democráticas que são estimuladas pelos movimentos sociais do campo constroem visões de partilhamento de autoridades e redistribuição de poder dentro da casa, a manifestação destas novas relações é traduzida quando há o rompimento de papeis estabelecidos por culturas machistas, que ditam as funções e cada gênero dentro da família. Embora não haja de forma total este rompimento, pois muitas mulheres ainda estão sujeitas a vários tipos de violências, identificamos nas mulheres militantes à disposição da denúncia, principalmente na formação das novas.

\section{UMA RESPOSTA PARA AS DUAS PERGUNTAS DE PARTIDA DA PESQUISA ${ }^{17}$}

Para a primeira pergunta, as nossas conclusões apontam que o lugar social da mulher dentro dos movimentos sociais do campo é diverso e move-se dependendo do tipo de movimento social - se composto por mulheres e homens ou só por mulheres - e do tema em que se situa a ação e a decisão a ser tomada. Se, se trata de um movimento social composto apenas de mulheres, o protagonismo é total, pois não encontram obstáculos machistas dentro da organização nem disputa entre homens e mulheres.

No entanto, a relação que elas têm com a organização dependerá da negociação no espaço doméstico com os maridos e companheiros, que não participando das ações do movimento criam dificuldades para uma participação mais intensa da mulher, em suas lutas por justas relações de gênero. Se o movimento é composto por homens e mulheres, o lugar do homem é mais definitivo que o da mulher, já que elas tenderão a ter visibilidades em decisões e áreas mais dominadas pela mulher, como as questões da educação, saúde e das relações de gênero.

\footnotetext{
${ }^{17}$ Qual o lugar social da mulher dentro dos movimentos sociais do campo? Como suas experiências dentro dos movimentos sociais têm contribuído para a (re)construção de novas subjetividades?
} 
Contudo, por se tratar do cumprimento das deliberações da organização, a mulher encontrará menor resistência de seus maridos/companheiros em participar das ações e decisões políticas do movimento social a que pertencem. Entretanto nos dois tipos de movimento social, o lugar social da mulher terá cor e orientação sexual, pois ambos reproduzem os padrões dominantes, e isto continua sendo o desafio democrático dos movimentos sociais, tanto de mulheres, quanto de homens e mulheres.

A segunda pergunta refere-se ao modo como experiências das mulheres dentro dos movimentos sociais têm contribuído para a (re)construção de novas subjetividades. Nessa direção as experiências que mais transformam as mulheres são aquelas que trabalham com a formação política e com as suas subjetividades. As dimensões corpo e sexualidade são mais aprofundadas nos movimentos só de mulheres, enquanto a formação política é mais forte nos movimentos de mulheres e homens.

A vivência da luta política como a participação nas marchas, fóruns, assembleias, aliada a utilização de símbolos, como bandeiras, camisetas e bonés são redentoras e dão intensidade e profundidade às experiências políticas que têm forte ligação com a construção de processos de identificação mais rebeldes. Este é um campo importante de afirmação da mulher, pois participar desses atos é ir ao encontro do mundo, é ampliar os horizontes, é se expressar coletivamente, quebrando o isolamento e o silenciamento dos sonhos e violências individuais.

Assim, é possível afirmar que estes momentos de militância carregam em si uma pedagogia de luta inovadora, que reconstrói a autoestima perdida pela subalternização naturalizada, de luta inovadora, de identidade e de desejos de emancipação, ao cravar uma centelha de poder nas mulheres, o que as transformam radicalmente.

\section{REFERÊNCIAS}

AMORIM, Jaime de e SOUZA, Rubneuza Leandro. O Movimento Sem Terra no estado de Pernambuco: rumo aos 20 anos rompendo cercas construindo história. In: Saberes - Revista do Observatório dos Movimentos Sociais, $\mathrm{n}^{\mathrm{0}}$ 1, p:40-52, jul, ago, set, out, 2008 
BOSERUP, E., Women's Role in Economic Development. New York: St. Martin's Press, 1970. BURAWOY, Michael (1991), The extended case method. In: M. Burawoy et al. (orgs), Ethonography unbounded. Power and resistance in the modern metropolis. Berkeley: University of California Press, 271-287.

BURAWOY, Michael (2000), Introduction: reaching for the global. In: M. Burawoy et al. (orgs), Global ethonography: forces, connections, and imaginations in a postmodern wold. Berkeley: University of California Press, 1-40.

ESCOBAR, Arturo. Actores, redes e novos produtores de conhecimento: os movimentos sociais e a transição paradigmática. In: SANTOS, Boaventura de Sousa (org) (2003). Conhecimento prudente para uma vida decente: “Um discurso sobre as ciências” revisitado. Porto: Edições Afrontamento, 2000

ESCOBAR, Arturo. Encountering Development: The making and unmaking of third world. Princeton: Princeton University Press, 1994.

GOHN, Maria da Glória. Teoria dos Movimentos Sociais: Paradigmas clássicos e 34 contemporâneos. São Paulo: Edições Loyola, 2002.

LAGE, Allene Carvalho. Lutas por Inclusão nas Margens do Atlântico: um estudo comparado entre as experiências do Movimento dos Sem Terra/Brasil e da Associação In Loco/Portugal. Coimbra: Universidade de Coimbra. Faculdade de Economia, 2005.

LAGE, Allene. Relatório de Projeto de Pesquisa - A mulher nos movimentos sociais do campo. Identidades, saberes de luta e educação. Um estudo comparado entre as mulheres do Movimento Sem Terra e as do Movimento das Mulheres Trabalhadoras Rurais. (Financiado pelo CNPq). Caruaru, 2012

LIMA, Míriam Monteiro de. Relatório Final de Projeto PIBIC - Violências contra a mulher e desigualdades nas relações de gênero: o trabalho pedagógico de dentro dos movimentos sociais do campo em Pernambuco para a igualdade de nas relações de gênero. CAA/UFPE, 2011. 
NETTA, Ranúzia Moreira de Lima. Relatório Final de Projeto PIBIC - Cativeiros da trabalhadora rural - raça/ etnia, geração e sexualidade: um estudo comparado entre as mulheres do MST-PE e as do MMTR-NE. CAA/UFPE, 2013

SANTOS, Boaventura de Sousa e RODRÍGUEZ, César. Introdução: para ampliar o cânone da produção. In: Produzir para viver: Os caminhos da produção não capitalista. Coleção Reinventar a emancipação social: Para novos manifestos. Vol. 2. p: 23-77. Rio de Janeiro: Record, 2002.

SANTOS, Boaventura de Sousa. Os conflitos urbanos no recife: o caso do Skylab. Revista Crítica de Ciências Sociais, nº 11, maio, p: 9-86. Coimbra: CES, 1983.

SANTOS, Boaventura de Sousa. Pela mão de Alice: o social e o político na pós-modernidade. São Paulo: Cortez, 1999.

SILVA, Andreia de Lima. Relatório Final de Projeto PIBIC - (Re)territorialidade: o protagonismo das mulheres no contexto da função social da terra dentro dos movimentos sociais do campo em Pernambuco. CAA/UFPE, 2012.

SILVA, Andreia de Lima. Relatório Final de Projeto PIBIC - Territorialidade e linguagens: refletindo a (re)construção das identidades das mulheres dentro dos movimentos sociais do campo de Pernambuco. CAA/UFPE, 2011

SILVA, Emanuely Arco Íris. Relatório Final de Projeto PIBIC - Movimentos sociais do campo: relações de gênero e educação. CAA/UFPE, 2010

SILVA, Maria Guadalupe de Araújo. Relatório Final de Projeto PIBIC - Identidades e (in)visibilidades: refletindo os processos de construção das ausências e subalternizações das mulheres dentro dos movimentos sociais do campo de Pernambuco. CAA/UFPE, 2011

SOUZA, João Francisco de. A democracia dos movimentos sociais populares: uma comparação entre Brasil e México. Recife: Edições Bagaço, 1999.

VIERA, Iasmim de Araujo. Relatório Final de Projeto PIBIC - "Quem sai aos seus não degenera". Que experiências políticas as trabalhadoras rurais ensinam às suas filhas? Um estudo comparado entre as mulheres do MST-PE e as do MMTR-NE. CAA/UFPE, 2013. 